\title{
Advanced Nanomaterials in Multimodal Imaging: Design, Functionalization, and Biomedical Applications
}

\author{
Zhe Liu, Fabian Kiessling, and Jessica Gätjens \\ Department of Experimental Molecular Imaging (ExMI), Helmholtz Institute for Biomedical Engineering, Medical Faculty, \\ RWTH Aachen University, Pauwelsstraße 20, 52074 Aachen, Germany
}

Correspondence should be addressed to Fabian Kiessling, fkiessling@ukaachen.de

Received 27 November 2009; Accepted 2 May 2010

Academic Editor: Donglu Shi

Copyright ( 2010 Zhe Liu et al. This is an open access article distributed under the Creative Commons Attribution License, which permits unrestricted use, distribution, and reproduction in any medium, provided the original work is properly cited.

The biomedical applications of nanoparticles in molecular imaging, drug delivery, and therapy give rise to the term "nanomedicine" and have led to ever-growing developments in the past decades. New generation of imaging probes (or contrast agents) and state of the art of various strategies for efficient multimodal molecular imaging have drawn much attention and led to successful preclinical uses. In this context, we intend to elucidate the fundamentals and review recent advances as well as to provide an outlook perspective in these fields.

\section{Introduction}

Nanotechnology, abbreviated as "nanotech", has witnessed rapid and broad developments over the past decades $[1,2]$. Nowadays, nanoscience is no longer confined to synthesis, characterization and simple derivation of nanomaterials, but has found its way to high-end applications and engineering in industrial sectors, such as electronics, communication, energy, advanced materials, space technology and biomedicine. The National Nanotechnology Initiative (NNI) defines nanosized particles as roughly $1-100 \mathrm{~nm}$ in dimensions, but this range might be extended up to $1000 \mathrm{~nm}$ [3]. They display novel optical, electronic and structural properties different from individual molecules or bulk particles. When applied in medical science, they give rise to the term of "nanomedicine" which has found more and more applications in preclinical, translational, and clinical research $[2,4,5]$. This will not only stimulate the progress of nanomaterial development, but also implicate unprecedented opportunities in the coming future for individualized diagnostic strategies and treatment methodologies in humans.

Among the vast applications of nanomedicine, molecular imaging is one of the most attractive and fastest growing research fields. As defined by the Society of Nuclear Medicine recently, molecular imaging is "visualization, characterization, and quantification of biological processes at the molecular and cellular levels in humans and other organisms" [6]. It is an emerging interdisciplinary research field that combines chemistry, biology, pharmacology, and medicine to detect biomedical or physiological processes in vitro and in vivo, and therefore allows for early detection of physiological changes, anatomical diagnosis of transformations, and provides valuable clinical information for treatment strategies for various diseases, such as cancer, inflammation, stroke, atherosclerosis, Alzheimer's disease, and many others [2, 79]. In addition, customizable nanoparticles have also been employed as efficient carriers for targeted drug delivery and therapeutic agents as well as for gene transportation.

\section{Nanoparticles}

Particles with nanoscale dimensions are expected to display special physical and biological behavior and unique interactions with biomolecules. Due to the large surface area of nanoparticles and inherent functionalities, structural modifications are readily achieved to alter their pharmacokinetics, prolong their vascular circulation life-time, improve their extravasation capacity, ensure an enhanced biodistribution 
TABLE 1: Characteristics of several representative nanoparticles and their biomedical applications.

\begin{tabular}{|c|c|c|c|c|c|c|}
\hline $\begin{array}{l}\text { Type of } \\
\text { nanoparticle }\end{array}$ & $\begin{array}{l}\text { Synthetic } \\
\text { protocol }\end{array}$ & Size range & $\begin{array}{l}\text { Possible surface } \\
\text { modifications }\end{array}$ & $\begin{array}{l}\text { Imaging } \\
\text { modality } \\
\text { applicable }\end{array}$ & $\begin{array}{c}\text { Possible } \\
\text { therapeutic } \\
\text { strategies }\end{array}$ & Reference \\
\hline Quantum dot & $\begin{array}{l}\text { colloidal } \\
\text { synthesis, } \\
\text { self-assembly, } \\
\text { viral assembly }\end{array}$ & $\begin{array}{l}\text { several to tens of } \\
\mathrm{nm}\end{array}$ & $\begin{array}{l}\text { lipids, polymer, } \\
\text { targeting ligands } \\
\text { or biomolecules }\end{array}$ & optical & $\mathrm{PDT}^{*}$ & {$[12]$} \\
\hline Dendrimer & $\begin{array}{l}\text { organic } \\
\text { chemistry } \\
\text { techniques }\end{array}$ & $\begin{array}{l}\text { several nm } \\
\text { varies from } \\
\text { different } \\
\text { "generation" }\end{array}$ & $\begin{array}{l}\text { charge, polymer, } \\
\text { targeting ligands } \\
\text { or biomolecules }\end{array}$ & MRI, optical & $\begin{array}{l}\text { drug and gene } \\
\text { delivery }\end{array}$ & {$[13]$} \\
\hline Liposome & $\begin{array}{c}\text { emulsion, } \\
\text { polymerization }\end{array}$ & $\begin{array}{c}\text { tens to } \\
\text { hundreds of } \mathrm{nm}\end{array}$ & $\begin{array}{l}\text { charge, polymer, } \\
\text { targeting ligands } \\
\text { or biomolecules, } \\
\text { viral protein } \\
\text { coating, }\end{array}$ & $\begin{array}{l}\text { MRI, optical, } \\
\text { radionuclide } \\
\text { imaging }\end{array}$ & $\begin{array}{l}\text { drug, gene and } \\
\text { protein delivery, } \\
\text { PDT, }\end{array}$ & {$[14]$} \\
\hline $\begin{array}{l}\text { Gold } \\
\text { nanoparticle }\end{array}$ & $\begin{array}{l}\text { biological } \\
\text { reduction, } \\
\text { colloidal } \\
\text { synthesis, vapor } \\
\text { precipitation }\end{array}$ & $\begin{array}{l}\text { several to } \\
100 \mathrm{~nm}\end{array}$ & $\begin{array}{c}\text { lipids, } \\
\text { polymeric shell, } \\
\text { targeting ligands } \\
\text { or biomolecules }\end{array}$ & CT, optical & $\begin{array}{c}\text { drug delivery, } \\
\text { PTT* }^{*}\end{array}$ & {$[15]$} \\
\hline $\begin{array}{l}\text { Carbon } \\
\text { Nanotube }\end{array}$ & $\begin{array}{l}\text { arc discharge, } \\
\text { laser ablation, } \\
\text { vapor } \\
\text { precipitation }\end{array}$ & tens of nm & $\begin{array}{l}\text { polymeric shell, } \\
\text { targeting ligands } \\
\text { or biomolecules }\end{array}$ & $\begin{array}{l}\text { MRI, optical, } \\
\text { radionuclide } \\
\text { imaging }\end{array}$ & $\begin{array}{c}\text { drug delivery, } \\
\text { PTT }\end{array}$ & {$[16]$} \\
\hline Microbubble & $\begin{array}{l}\text { emulsion, } \\
\text { layer-by-layer } \\
\text { fabrication, } \\
\text { polymerization }\end{array}$ & tens to $1000 \mathrm{~nm}$ & $\begin{array}{l}\text { polymeric shell, } \\
\text { targeting ligands } \\
\text { or biomolecules }\end{array}$ & US & $\begin{array}{l}\text { drug, gene and } \\
\text { protein delivery }\end{array}$ & {$[17]$} \\
\hline Iron Oxide & $\begin{array}{l}\text { coprecipitation, } \\
\text { decomposition, } \\
\text { microemulsion, } \\
\text { sol-gel, thermal }\end{array}$ & $\begin{array}{l}\text { several to tens of } \\
\mathrm{nm}\end{array}$ & $\begin{array}{l}\text { charge, dextran, } \\
\text { lipids, polymer, } \\
\text { targeting ligands } \\
\text { or biomolecules }\end{array}$ & MRI & $\begin{array}{l}\text { siRNA delivery, } \\
\text { PTT }\end{array}$ & {$[18]$} \\
\hline Micelle & microemulsion & tens of nm & $\begin{array}{l}\text { charge, polymer, } \\
\text { targeting ligands } \\
\text { or biomolecules }\end{array}$ & $\begin{array}{l}\text { MRI, optical, } \\
\text { radionuclide } \\
\text { imaging }\end{array}$ & $\begin{array}{l}\text { drug and gene } \\
\text { delivery, PDT }\end{array}$ & {$[19]$} \\
\hline Adenovirus & $\begin{array}{l}\text { replication in } \\
\text { host nucleus }\end{array}$ & $\begin{array}{l}\text { tens of to } \\
100 \mathrm{~nm}\end{array}$ & $\begin{array}{l}\text { charge, polymer, } \\
\text { targeting ligands } \\
\text { or biomolecules }\end{array}$ & MRI, optical & gene delivery & {$[20]$} \\
\hline $\begin{array}{l}\text { Silica } \\
\text { nanoparticle }\end{array}$ & $\begin{array}{c}\text { chemical } \\
\text { polymerization, } \\
\text { microemulsion, } \\
\text { sol-gel }\end{array}$ & $\begin{array}{l}\text { tens of to } \\
100 \mathrm{~nm}\end{array}$ & $\begin{array}{l}\text { charge, polymer, } \\
\text { targeting ligands } \\
\text { or biomolecules }\end{array}$ & MRI, optical & $\begin{array}{l}\text { drug and gene } \\
\text { delivery }\end{array}$ & {$[21]$} \\
\hline
\end{tabular}

*Abbreviations: PDT= Photodynamic therapy; PTT= Photothermal therapy.

in vivo, and lead to a sustained and controllable delivering efficacy for drug cargoes $[10,11]$. Furthermore, when specific targeting ligands are conjugated to nanoparticles, targeted binding capability to diseased regions can be realized. Nanocarriers will penetrate through microvessels with enhanced permeability and then be taken up by cells, thus offering highly-selective payload accumulation at target sites.

More and more nanoparticle-based structures are currently under investigation and some well-studied nanoparticles include quantum dots, dendrimers, nanotubes, liposomes, micelles, gold nanoparticles, and nano/microbubbles.
Different types of nanoparticles have different biomedical purposes and are being used for medical molecular imaging, controlled drug delivery, and targeted therapy. The characteristics and biomedical applications of some representative nanoparticles have been listed in Table 1.

It should be noted that the knowledge on the effect of nanoparticles on human health is very limited. Thus, nanotoxicology, which is the science examining the effects of artificial nanostructures on living organisms is of great importance. For example, nanoparticles can penetrate into the cells and selectively accumulate. They can be transported across the epithelial and endothelial cells via transcytosis. 


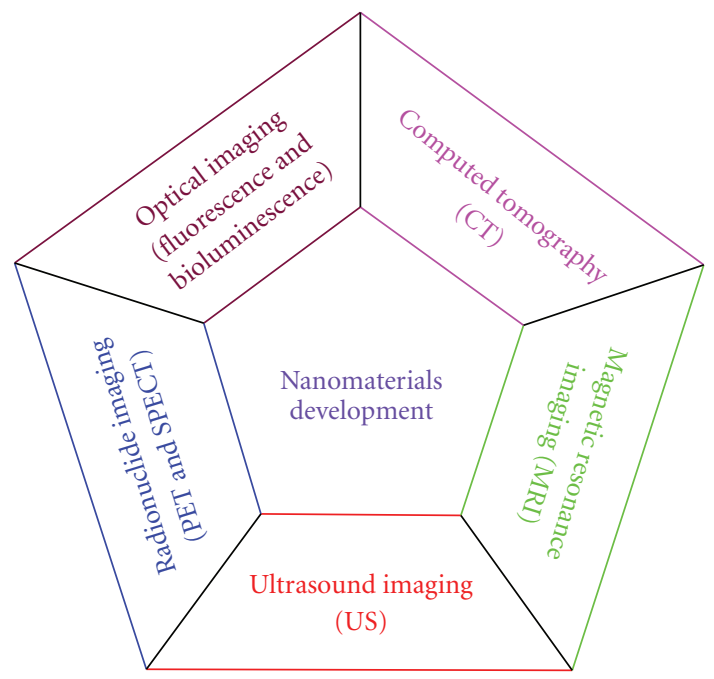

FIGURE 1: Illustration for nanomaterial applications in various imaging modalities.

Further, they might travel along the dendrites, axons and the blood and lymphatic vessels provoking oxidative stress and inflammation [22]. However, appropriate chemical modifications on the surface can be readily implemented to render them qualified for medical uses even though some "naked" nanoparticles are highly cytotoxic and cannot be applied in humans directly.

\section{Molecular Imaging}

During the past decades, many traditional medical imaging techniques have been established for routine experimental and clinical uses. These imaging modalities, such as optical imaging (OI), computed tomography (CT), magnetic resonance imaging (MRI), ultrasound (US), and radionuclide imaging (PET/SPECT) have been widely applicable to and made superb performance in experimental small animal imaging, preclinical imaging and clinical human body imaging, diagnosis and treatments [23-26] (Figure 1).

Molecular imaging differs from traditional imaging in that probes known as biomarkers are used to help image particular targets or pathways. It is required that biomarkers highly specifically interact with their surroundings, and in turn alter the image according to molecular changes occurring within the area of interest. Molecular imaging agents are endogenous molecules or exogenous probes used to visualize, characterize, and quantify biological processes in living systems. Different imaging techniques in terms of sensitivity, resolution and complexity often require specific contrast agents to obtain satisfactory contrast enhancement in visualization reconstruction. Here, we will give a brief description on the properties of various imaging modalities, the nature of contrast enhancement and selected efficacious contrast agents commonly used at present. A detailed summary of characteristics, comparisons, and practical applications of these common imaging modalities is given in Table 2 .
Optical imaging is a relatively lowcost, noninvasive and extensively used imaging technique, in that light is taken as the most readily available and versatile imaging radiation source in nature. Fluorescence imaging (FLI) and bioluminescence imaging (BLI) are two major techniques in optical imaging to analyze the propagation of nonionizing radiation, light photons through a medium such as tissue. Proteic fluorophores (green fluorescent protein/GFP, red fluorescent protein/RFP) and organic/inorganic fluorescent dyes are popular imaging agents in fluorescence imaging [27]. Besides that, quantum dots and iron oxide nanoparticles with fluorescent shell structure can also be employed as fluorescent imaging building blocks for efficient molecular fluorescence imaging in vitro and in vivo.

Computed tomography (CT) is founded on the exploitation of X-ray scanning, its attenuation in tissues and computed image reconstruction to obtain morphologic and vascular information within the body. Different components inside the body, such as soft tissue, fat, water and air, have different capability of X-ray absorption and attenuation. In this way, an anatomical visualization of body structures (lung, bones, tumor, and others) can be imaged with high contrast performance. Iodine, barium salt and gastrografin have been common CT contrast agents in clinics to highlight blood vessels, stomach and gastrointestinal organs. Theoretically, CT is not a molecular imaging modality as the sensitivity for contrast material is not sufficient to detect as low amounts as would be bound to a molecular target. However, this will not be an obstacle in the application of multimodal imaging approaches if CT contrast agents are structurally modified to meet other imaging requirements such as contrasting the blood pool or organs of the reticulo-endothelial system (RES).

Magnetic resonance imaging (MRI) is a noninvasive medical diagnostic technique. Although certain endogenous contrast can be achieved in the process of nuclei excitation and relaxation of magnetic spins, specific exogenous contrast agents are often required to give an acceptable MRI image with high spatiotemporal resolution, sensitivity, specificity, and volumetric coverage. The most commonly used contrast agents for MRI include paramagnetic complexes $\left(\mathrm{Ga}^{3+}\right.$ or $\mathrm{Mn}^{2+}$ based chelates), paramagnetic ion nanoparticles $\left(\mathrm{Gd}_{2} \mathrm{O}_{3}\right.$ and $\left.\mathrm{MnO}\right)$, and superparamagnetic iron oxide nanoparticles $\left(\mathrm{Fe}_{3} \mathrm{O}_{4}, \mathrm{FeCO}\right.$, and $\left.\mathrm{MnFe}_{2} \mathrm{O}_{4}\right)$ [28, 29]. Novel MRI contrast agents have been produced as derivatives of these three species, such as magnetic dendrimers, liposomes, and micelles. It is notable that the major advantage of MRI is its high spatial resolution $(25-100 \mu \mathrm{m}$ level) and the excellent tissue contrast. In this context, MRI overruns other molecular imaging approaches up to date, and it is available for both morphological and functional assessments, while a certain quantity of contrast agents (approximately $\mu \mathrm{g}$ to $\mathrm{mg}$ ) is necessary for the relatively time-consuming imaging process.

Ultrasound (or ultrasonography) [30] is one of the most applied medical imaging techniques. The major advantage of US imaging is low cost, high safety and readily availability for portable devices. In experimental ultrasound imaging, gas-filled microbubbles, perfluorocarbon emulsions and 
TABLE 2: Comparison of various imaging modalities in preclinical use.

\begin{tabular}{|c|c|c|c|c|c|}
\hline $\begin{array}{l}\text { Imaging } \\
\text { modality }\end{array}$ & Optical imaging & $\begin{array}{l}\text { Computed } \\
\text { tomography }\end{array}$ & $\begin{array}{l}\text { Magnetic } \\
\text { resonance } \\
\text { imaging }\end{array}$ & Ultrasound & $\begin{array}{l}\text { Radionuclide } \\
\text { imaging }\end{array}$ \\
\hline $\begin{array}{l}\text { Source of } \\
\text { detection }\end{array}$ & $\begin{array}{c}\text { visible or } \\
\text { near-infrared light }\end{array}$ & X-ray & $\begin{array}{l}\text { magnetic field, } \\
\text { radiowaves }\end{array}$ & ultrasonic waves & $\gamma$-ray \\
\hline $\begin{array}{l}\text { Common } \\
\text { imaging probes }\end{array}$ & $\begin{array}{c}\text { fluorescent dyes, } \\
\text { quantum dots }\end{array}$ & $\begin{array}{l}\text { heavy atom- } \\
\text { containing } \\
\text { contrast agents, } \\
\text { for example, } \\
\text { iodine, barium } \\
\text { and gadolinium } \\
\text { salts }\end{array}$ & $\begin{array}{l}\text { paramagnetic or } \\
\text { superparamag- } \\
\text { netic contrast } \\
\text { agents, for } \\
\text { example, } \\
\text { gadolinium, } \\
\text { manganese } \\
\text { compounds and } \\
\text { magnetofluids } \\
\left(\mathrm{Fe}_{3} \mathrm{O}_{4}\right)\end{array}$ & microbubbles & 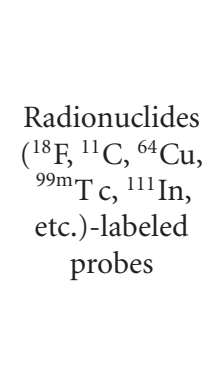 \\
\hline Advantages & $\begin{array}{l}\text { inexpensive, } \\
\text { low-cost, easy } \\
\text { operation }\end{array}$ & $\begin{array}{l}\text { anatomical } \\
\text { imaging, } \\
\text { applicable for } \\
\text { humans }\end{array}$ & $\begin{array}{l}\text { high spatial } \\
\text { resolution, } \\
\text { combines } \\
\text { morphological } \\
\text { and functional } \\
\text { imaging, no } \\
\text { tissue } \\
\text { penetrating } \\
\text { limit, applicable } \\
\text { for humans }\end{array}$ & $\begin{array}{c}\text { safety, real-time, } \\
\text { low cost, wide } \\
\text { availability, easy } \\
\text { handling }\end{array}$ & $\begin{array}{l}\text { high sensitivity, } \\
\text { quantitative, no } \\
\text { penetration } \\
\text { limit }\end{array}$ \\
\hline Disadvantages & $\begin{array}{l}\text { photobleaching, } \\
\text { limited tissue } \\
\text { penetrating depth, } \\
\text { surface-weighted, } \\
\text { relatively low spatial } \\
\text { resolution, } \\
\text { autofluorescence } \\
\text { disturbance }\end{array}$ & $\begin{array}{l}\text { radiation risks, } \\
\text { limited soft } \\
\text { tissue } \\
\text { resolution, not } \\
\text { quantitative }\end{array}$ & $\begin{array}{l}\text { relatively low } \\
\text { sensitivity, } \\
\text { time-consuming } \\
\text { scan and } \\
\text { processing, high } \\
\text { cost }\end{array}$ & $\begin{array}{l}\text { limited } \\
\text { resolution and } \\
\text { sensitivity, low } \\
\text { data } \\
\text { reproducibility }\end{array}$ & $\begin{array}{l}\text { low spatial } \\
\text { resolution, } \\
\text { radiation risks, } \\
\text { high cost }\end{array}$ \\
\hline $\begin{array}{l}\text { Some practical } \\
\text { applications }\end{array}$ & $\begin{array}{l}\text { cellular/intracellular } \\
\text { expression, } \\
\text { trafficking or } \\
\text { movement } \\
\text { monitoring of } \\
\text { reporter/gene }\end{array}$ & $\begin{array}{l}\text { bone and tumor } \\
\text { imaging, fused } \\
\text { image with } \\
\text { other modalities }\end{array}$ & $\begin{array}{l}\text { cell trafficking, } \\
\text { morphological } \\
\text { reporter/gene } \\
\text { expression, } \\
\text { cerebral and } \\
\text { coronary } \\
\text { angiography in } \\
\text { clinics }\end{array}$ & $\begin{array}{c}\text { potential } \\
\text { application in } \\
\text { drug delivery } \\
\text { and controlled } \\
\text { release, echocar- } \\
\text { diography and } \\
\text { intracranial } \\
\text { neoplasm in } \\
\text { clinics }\end{array}$ & $\begin{array}{c}\text { noninvasive } \\
\text { evaluation of } \\
\text { pharmacokinet- } \\
\text { ics and } \\
\text { metabolism of } \\
\text { drugs, cerebral, } \\
\text { cardiac and } \\
\text { tumor imaging } \\
\text { in clinics }\end{array}$ \\
\hline
\end{tabular}

colloidal suspensions are commonly used contrast agents for blood pool enhancement, lesion characterization and perfusion imaging. These contrast agents can resonate in an ultrasound beam, undergo shell oscillations, and expand and contract in response to acoustic pressure changes and thus achieve the ultrasound contrast enhancement. Many contrast agents are made from biocompatible and biodegradable materials, exhibit excellent vascular circulation properties, and have proven to be safe and stable in vivo, which make them suitable candidates for US imaging and medical usage.

Radionuclide imaging, as this name implies, implements radioactive nuclei as the source for detection and image reconstruction [31]. Positron emission tomography (PET) and single photon emission computed tomography (SPECT) are two major types of radionuclide imaging modalities.
Various radionuclides, such as ${ }^{16} \mathrm{~F},{ }^{64} \mathrm{Cu}$, and ${ }^{68} \mathrm{Ga}$ (for PET) and ${ }^{125} \mathrm{I},{ }^{111} \mathrm{In}$, and ${ }^{99 \mathrm{~m}} \mathrm{Tc}$ (for SPECT) can be applied as radioisotopes, respectively. The major disadvantage of radionuclide imaging is poor spatial resolution $(1-2 \mathrm{~mm}$ in clinical scanners). High sensitivity ( $\mathrm{nmol} / \mathrm{L})$, relatively low dose (ng) of radiotracers for detection, quantitative analysis and no limitation of tissue penetration facilitate the possibility of preclinical and translational applications, as well as noninvasive evaluations of pharmacokinetics properties for new drugs. For example, 2-[ $\left.{ }^{18} \mathrm{~F}\right]$ fluoro-2deoxy-D-glucose $\left(\left[{ }^{18} \mathrm{~F}\right] \mathrm{FDG}\right)$ has been a widely used PET imaging probe for both cancer diagnosis and radiotherapy [32].

Among all the molecular imaging modalities, no single modality is perfect to meet all the requirements in medical 
applications. As a consequence there is a clear trend towards hybrid imaging modalities such as PET-CT, PET-MRI, SPECT-CT, as well as optical imaging and CT. Also the combination of ultrasound and MRI is attractive, which particularly holds true for the real time monitoring of high focused ultrasound therapy. Thus, developing dualmodal imaging probes for both ultrasound and MRI, and combining the advantages of these two modalities can offer synergistic advantages in providing more valuable diagnostic information and treatment strategies [33].

Although it is challenging to integrate dual or multimodal imaging properties into a single probe (engineered molecule), this concept is probably the most promising and convenient approach to overcome current drawbacks in one single imaging modality. In particular, as nanoparticles have large surface area and multiple functional groups on the shell, it is possible to employ appropriate structural modifications and engineering along with binding ligands conjugation to produce multifunctional nanoparticles for multimodal molecular imaging. Nowadays, more and more nanoparticle-based dual or multimodal imaging probes (or contrast agents) have been developed and applied to multimodal functional imaging in living subjects.

\section{Structure Design and Functionalization Strategies of Nanoparticles}

To devise multimodal imaging agents or therapeutic probes with nanoparticles, several parameters have to be taken into considerations: (i) toxicity of nanoparticles for living subjects and humans; (ii) any possible metabolites after vascular circulation or cell uptake; (iii) biocompatibility and biodegradability to avoid harmful accumulations in organs, tissues or blood; (iv) availability for chemical modifications of nanoparticles; and (v) comprehensive assessments of fabricated nanoparticles in vitro and in vivo before practical applications for living subjects or humans.

Generally, common methodologies for structure design and functionalization strategies of nanoparticles can be summarized as follows.

(a) Selection and Fabrication of Nanoparticles Core. What kind of nanoparticle is eligible to be the core and how to fabricate the structure of imaging probes are determined by the imaging purposes and a specific imaging modality.

(b) Shell Structure Synthesis. The shell structure usually serves more complicated purposes than the core of nanoparticles. It may protect the core from the external microenvironment and improve the core stability and physical property. Shell materials bearing good biocompatibility will reduce unexpected immunophysiological side effects in vivo and facilitate fast clearance of nanoparticles from the body. As far as drug delivery and therapy are concerned, the shell structure defines the efficiency of shell burst and controllable release of therapeutic drugs encapsulated in the core. On the other hand, the nanoparticle shell could be considered as a cargo for imaging probes (or contrast agents), drug payload or therapeutic agents incorporation so as to strengthen the integral functional efficacy.

(c) Surface Modifications. As the outer interface of the shell might be too sensitive when exposed to biomedium, such as blood, plasma or receptors at the binding sites, surface coatings with stabilizer or emulsions (surfactants, polymers, etc.) may be necessary to maintain the nanoparticles' stability. For targeted molecular imaging, drug delivery and therapy, specific targeting ligands on the nanoparticle surface are desired to be conjugated to biomolecules (small molecules, peptides, antibodies or, proteins). Apart from that, PEGylations (for pharmacokinetics adjustment) or spacer/linker incorporations (for conjugation or segregation of biomolecules) on the surface may be possibly involved for certain imaging or therapy purposes. Several important bioconjugation strategies for nanoparticle surface functionality are summarized in Figure 2 [34].

Although various functionalities, targeting ligands, imaging probes and therapeutic payloads could be incorporated within the inner structure of nanoparticles or conjugated on the surface by different modification protocols as illustrated in Figure 3, not every possible modification unit is all necessary for an individual nanoparticle. Specific imaging modalities or defined therapeutic purposes will direct to necessary strategies for structure design and functionalization and thus lead to an optimal performance in practical medical applications.

\section{Biomedical Applications of Nanoparticles in Imaging}

The biomedical applications of nanoparticles (or nanomedicine) are rooted in the advanced functional design, and have been realized in preclinical experimental diagnosis. In the long run, they will contribute to personalized clinical treatment on the basis of molecular profiles of each individual patient. The development is rapid and multidirectional, but at present is still in its early stages (Figure 4). The main applications of nanoparticles can be divided into several major directions: diagnostic molecular imaging, delivery of drug and gene, and targeted therapy $[35,36]$. In the following context, we intend to review the state-of-the-art imaging applications in recent years.

5.1. Iron Oxide Nanoparticles. Iron oxide nanoparticles (IONPs) are representative contrast agents which can be used for $T_{2}$ - and $T_{2}{ }^{*}$-weighted MRI molecular imaging [37]. There are several methods for chemical synthesis of iron oxide nanoparticles. Among these methods, coprecipitation of $\mathrm{Fe}^{2+}$ and $\mathrm{Fe}^{3+}$ ions in a basic aqueous media $(\mathrm{NaOH}$ or $\mathrm{NH}_{4} \mathrm{OH}$ solutions) is the simplest way, but usually polydispersed, poorly crystallized nanoparticles are obtained. To avoid these disadvantages, thermal decomposition method was employed to produce iron oxide nanoparticles with monodispersity and uniform crystalline. Subsequently, the hydrophobic iron oxide nanoparticles can be coated with phospholipids, silica, or amphiphilic polymers as shells to 


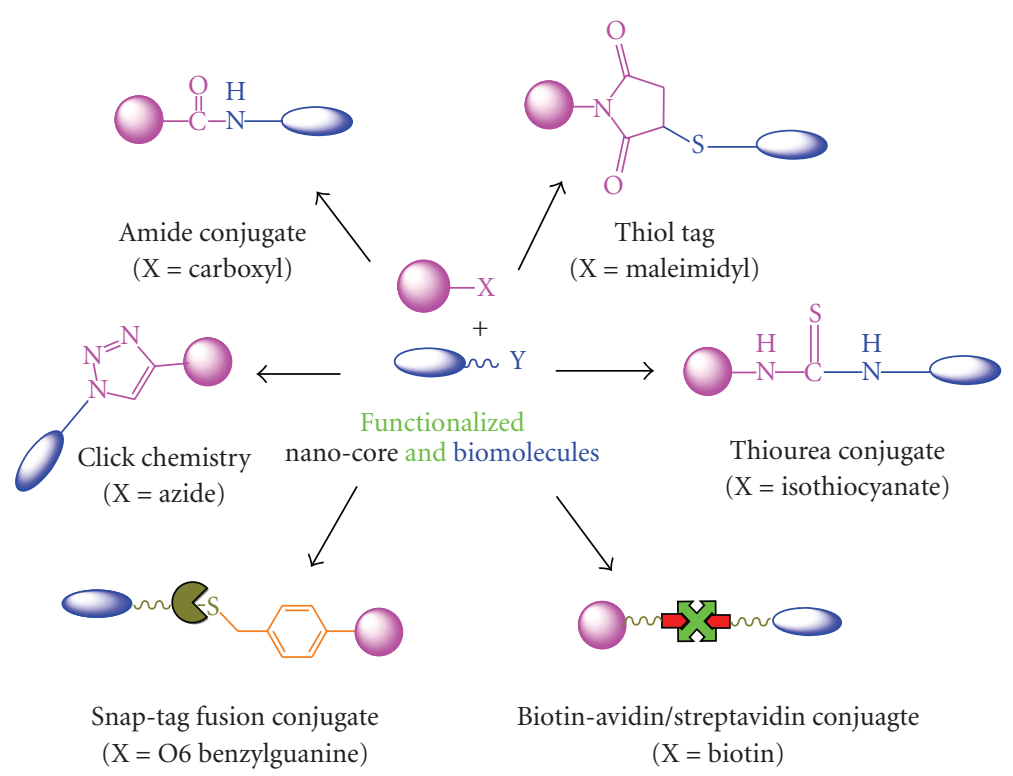

FIgURE 2: Bioconjugation strategies for chemical modification on nanoparticle surface.

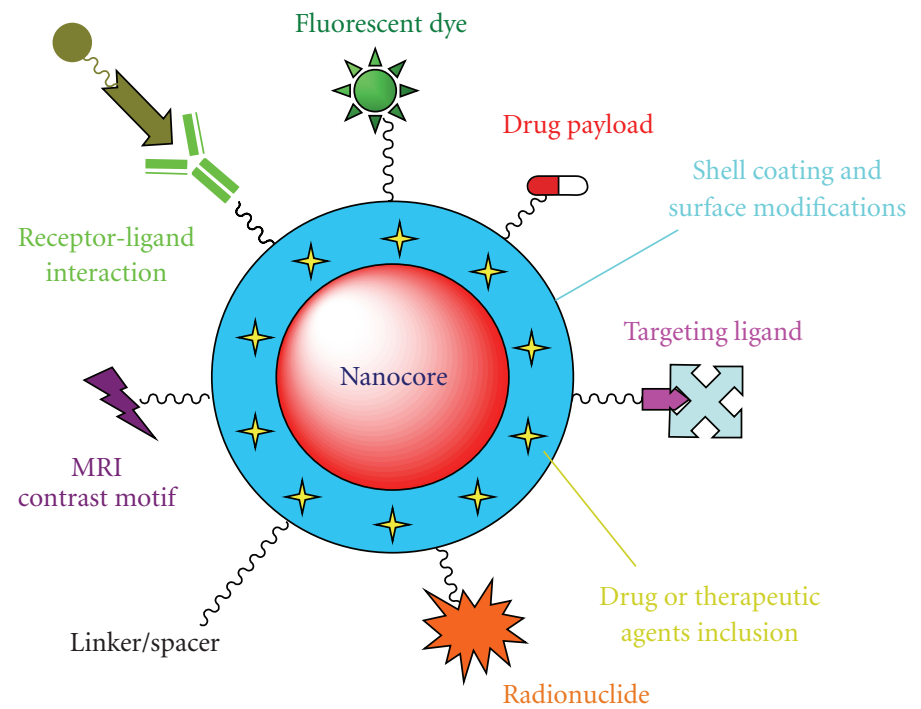

FIGURE 3: Scheme of multifunctional nanoparticle for molecular imaging, drug delivery and therapy. Optionally functionalized and devised nanoparticles could be achieved for individualized diagnosis and treatments.

display good solubility and biocompatibility in vivo. Iron oxide nanoparticles can be classified into three subtypes in terms of different size distributions of particle population: VSOP (very small superparamagnetic iron oxide nanoparticles, diameter $<10 \mathrm{~nm}$ ), USPIO (ultrasmall superparamagnetic iron oxide nanoparticles, diameter $\sim 20 \mathrm{~nm}$ ) and SPIO (superparamagnetic iron oxide nanoparticles, diameter $>30 \mathrm{~nm}$ ). Table 3 has listed recent developments of IONPbased contrast agents that are intended for multimodal imaging and drug delivery.

Synergistic effects of different imaging modalities will lead to multimodal imaging developments and applications in in vitro assay, ex vivo assessment, and in vivo diagnosis of living subjects including humans. Among multimodal imaging strategies, MRI-optical dual modal imaging can be relatively easily achieved [53]. In 2002, Weissleder's group developed a so-called smart crosslinked iron oxide (CLIO)based Cy5.5-arginyl peptide conjugated nanoparticle for in vivo MR and near-infrared fluorescence (NIRF) dual imaging [38]. This probe could be prepared by conjugation of the arginyl peptides $\left(\mathrm{R}_{4}\right)$ to CLIO amine via either a disulfide linkage or a thioether linker, followed by the attachment of the indocyanine dye Cy5.5 as a NIR fluorescent probe. Since the absorbance spectra for all biomolecules (hemoglobin, water and lipids in living systems) reach a minimal absorption coefficient in the NIR wavelength range of 650-900 nm, this could minimize tissue autofluorescence and provide a clear imaging window for successful image 
TABLE 3: A chronological list of various IONP-based nanoparticles as MR imaging probes*.

\begin{tabular}{|c|c|c|c|c|}
\hline SPIO-based nanoparticles & Application & Particle size $(\mathrm{nm})$ & Relaxivity $\left(\mathrm{mM}^{-1} \mathrm{~s}^{-1}\right)$ & Reference \\
\hline Cy5.5-R 4 -SS-CLIO & MR/optical in vivo imaging & $68 \pm 13$ & $r^{1}=27.8 ; r^{2}=91.2$ & {$[38]$} \\
\hline Cy5.5-CLIO-EPPT-FITC & MR/optical in vivo imaging for uMUC-1 tumor & 35.8 & $r^{1}=26.43 ; r^{2}=53.44$ & [39] \\
\hline Cy5.5-Cltx-PEG-USPIO & MR/optical in vitro imaging for glioma brain tumor & $10.5 \pm 1.5$ & n.a. & {$[40]$} \\
\hline $\mathrm{CoFe}_{2} \mathrm{O}_{4} @ \mathrm{SiO}_{2}(\mathrm{FITC})$ & MR/optical in vitro imaging & 60 & n.a. & {$[41]$} \\
\hline $\mathrm{DySiO}_{2}-\left(\mathrm{Fe}_{3} \mathrm{O}_{4}\right) \mathrm{n}$ & MR/optical in vitro imaging & 46 & $r^{2}=397$ & {$[42,43]$} \\
\hline $\mathrm{FePt}-\mathrm{Au}$ & MR in vitro imaging & $6(\mathrm{FePt})-10(\mathrm{Au})$ & $r^{2}=58.7$ & {$[44]$} \\
\hline PVLA-USPIO & MR in vivo imaging for hepatocytes & $25.8 \pm 6.1$ & n.a. & {$[45]$} \\
\hline $\mathrm{SPIO} @ \mathrm{SiO}_{2}(\mathrm{FITC})$ & MR in vivo imaging and human stem cell labeling & 50 & $r^{2}=128$ & {$[46,47]$} \\
\hline $\mathrm{USPIO} @ \mathrm{SiO}_{2}$ & MR in vitro imaging and cell labeling & $9.9 \pm 1.6$ & $r^{1}=0.55 ; r^{2}=339.80$ & {$[48]$} \\
\hline APTMS-USPIO-cRGD & MR in vitro imaging for $\alpha_{v} \beta_{3}$ integrin & $10 \pm 3$ & $r^{1}=1.0 ; r^{2}=134.0$ & {$[49]$} \\
\hline USPIO-4-MC-cRGD & MR in vivo imaging for $\alpha_{v} \beta_{3}$ integrin & $8.4 \pm 1.0$ & $r^{2}=165.0$ & {$[50]$} \\
\hline VSOP-Cys-PEG-LCP & MR in vitro imaging for lung tumors & $6.2 \pm 0.9$ & $r^{1}=11.5 ; r^{2}=142.0$ & {$[51]$} \\
\hline SPIO-Doxo@LCP-MFM & MR in vitro imaging and drug delivery & $48 \sim 60$ & $r^{2}=400$ & {$[52]$} \\
\hline
\end{tabular}

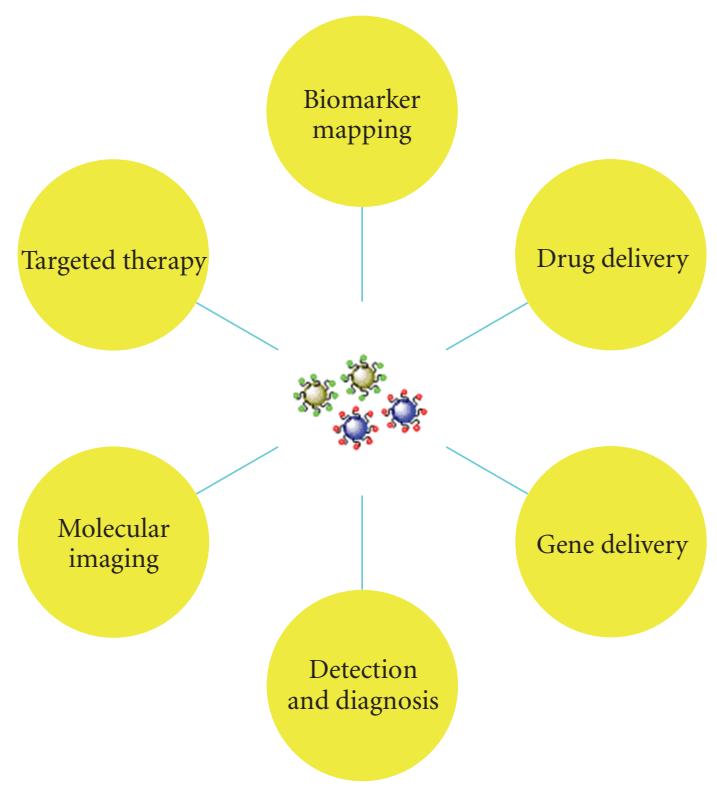

Figure 4: State of the art of multi-directional applications in nanomedicine.

visualization. After the administration of this probe via subcutaneous injection into nude mice, the lymph nodes were negatively enhanced in MR images and simultaneously visualizable in NIR fluorescent imaging.
Moore et al. designed a novel imaging probe consisting of CLIO-Cy5.5 conjugated to peptide EPPT which was specifically recognizing underglycosylated mucin-1 antigen (uMUC-1) on various tumor cells [39]. The synthesized probe displayed high specificity toward a variety of uMUC1-positive human adenocarcinomas in vitro. Additionally, in vivo MR and NIRF imaging showed specific accumulation of this probe on uMUC-1-positive tumors and virtually no signal in control tumors. Thus, this imaging probe would be applied to not only early detection and staging of the recurrence of tumors, but also for monitoring of therapeutic efficacy. Apart from small peptides, Chlorotoxin, a larger 36-amino acid peptide purified from the venom of the giant Israeli scorpion and with high affinity to MMP-2 endopeptidase, could be conjugated to USPIO for imaging glioma tumors. Veiseh et al. synthesized a multifunctional nanoprobe consisting of Cy5.5-Cltx motifs on the surface of USPIO via PEGylation linkage for both MR imaging and fluorescence microscopy [40]. This nanoprobe has been proved to be highly stable and showed prolonged retention within targeted cells (at least $24 \mathrm{~h}$ ), which is advantageous in intraoperative imaging applications compared to conventional optical fluorophores. A preferential uptake and a high degree of internalization of the nanoprobe conjugates by glioma cells versus control normal cells were also observed in in vitro experiments.

Cheon's group developed a "core-satellite" structured $\mathrm{DySiO}_{2}-\left(\mathrm{Fe}_{3} \mathrm{O}_{4}\right)_{n}$ nanoparticle which demonstrated high 


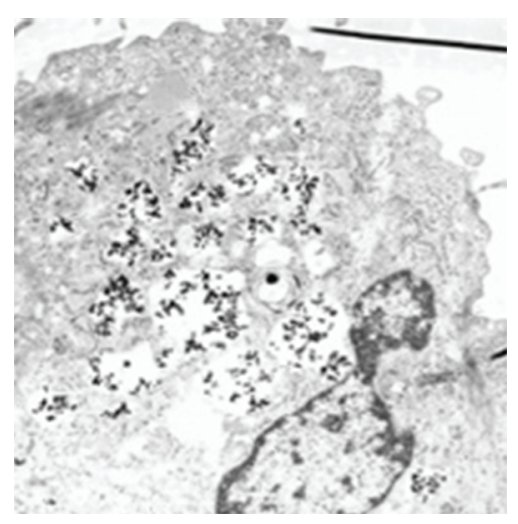

(a)

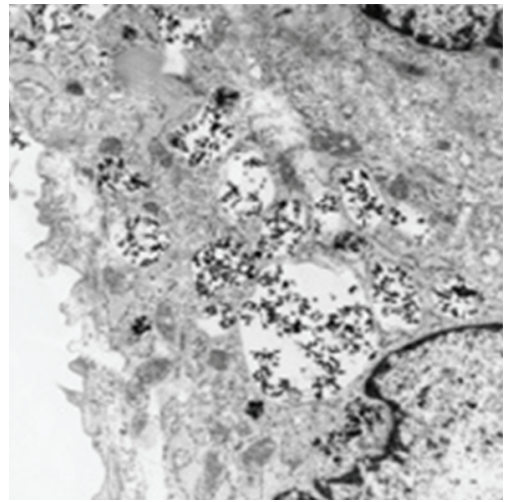

(b)

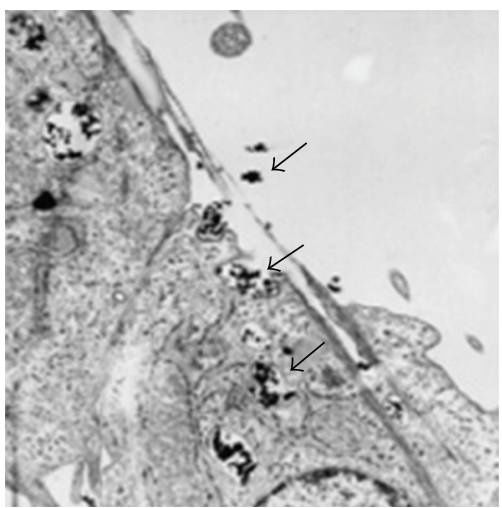

(d)

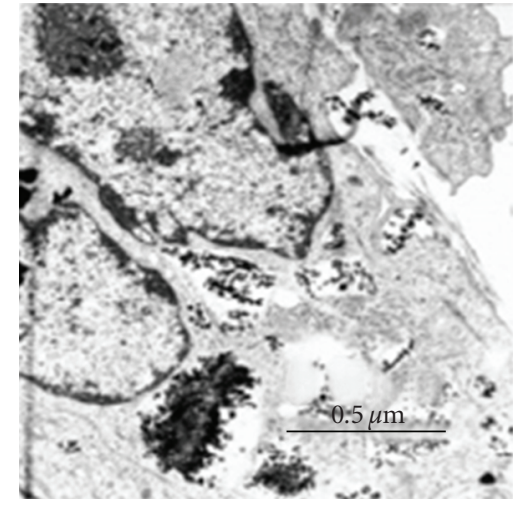

(c)

FIGURE 5: TEM images of immortalized progenitor cells $6 \mathrm{~h}$ after incubation with (a) silica-, (b) APTMS- and (c) AEAPTMS-coated USPIO particles at an iron concentration of $0.3 \mu \mathrm{mol} / \mathrm{mL}$. The particles were located intracellularly and most of them were aggregated in large lysosomes. Image (d) shows the process of USPIO nanoparticle uptake into the cells. (Reprinted with permission from [48]).

performance of $T_{2}$-weighted contrast-enhanced MR images as well as good fluorescent properties for the detection of polysialic acids (PSAs) expressed on neuroblastoma and many other cell lines [42]. A similar concept could also be applied to MR imaging of targeted specific adenovirus gene delivery [43]. Lys residue-containing adenovirus and MnMEIO (manganese-doped magnetism engineered iron oxide) could be incorporated into the same cross-linker sulfo-SMCC. When the hybrid nanoparticles were applied to target specific delivery to coxsackie and adenovirus receptor (CAR)-expressed U251 cell lines, a dark MR contrast was apparently observed compared to control nontreated and free MnMEIO-treated cell lines. Targeted infection and gene delivery have also been proved successful by utilizing these virus-magnet hybrid nanoparticles.

$\mathrm{Lu}$ and coworkers reported a silica-coated core-shell SPIO nanoparticle with incorporation of fluorescein isothiocyanate (FITC), namely SPIO@SiO ${ }_{2}$ (FITC), for MRIdetectable human mesenchymal stem cells (hMSCs) labeling [46]. The SPIO nanoparticles were synthesized by thermal decomposition and stabilized with oleic acid and oleyl amine. Afterwards, the hydrophobic nanoparticles were coated with dye-doped silica shells via a reversed microemul- sion system. This magnetic vector displayed perfect stability (7 days) after differentiations and could efficiently label hMSCs via clathrin- and actin-dependent endocytosis. This was the first report that hMSCs could be labeled with MRI contrast agents and also monitored in vivo with a clinical 1.5, T MRI scanner.

Recently, our group developed the silica- and alkoxysilane-coated USPIO nanoparticles and successfully applied them to MRI-guided cell-labeling and cell-tracking in vitro [48]. After surface coating of USPIO with silica, APTMS and AEAPTMS, respectively, a narrow size distribution with mean diameter of about $10 \mathrm{~nm}$ was observed, which indicated no significant size difference compared to uncoated USPIO nanoparticles. In both MR phantom imaging and cell uptake experiments, silicacoated USPIOs exhibited the highest $T_{2}$ relaxivity and maximum cellular iron concentration at same incubation conditions, compared to APTMS- and AEAPTMS-coated ones. Interestingly, a process of internalization of USPIO particle uptake into the cells could be observed by TEM as shown in Figure 5. After attachment of the USPIO particles to the cell plasma membrane, they were incorporated by small pinocytotic vesicles with membrane specifications (arrows in Figure 5(d)). 


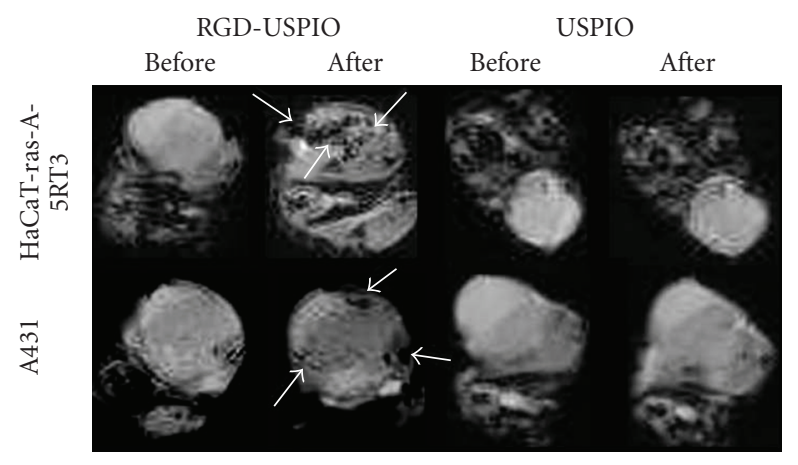

FIgURE 6: $T_{2}{ }^{*}$-weighted MR images of nude mice bearing s.c. HaCaT-ras-A-5RT3 (top) and A431 (bottom) tumors before and $6 \mathrm{~h}$ after i.v. injection of RGD-USPIO and USPIO, respectively. (Reprinted with permission from [49]).

On basis of these silica- and alkoxysilane-coated USPIO nanoparticles and as an extension of this research, Jugold et al. developed a kind of MRI contrast agent for selectively targeting urokinase-type plasminogen activator receptors (uPARs) when USPIOs were conjugated with polypeptides as binding-directed biomolecules [54]. This approach would be promisingly applied as a useful diagnostic strategy to more diseases if associated with PET and SPECT as synergistic imaging modalities.

Some biological and physiological processes are essential for development of malignant tumors and can be important targets for cancer diagnosis, prognosis and therapy. Angiogenesis is a crucial step for tumor growth, extension and even metastasis [55]. After surface conjugation with receptors or specific biomolecules, USPIO-based tumortargeted nanoparticles could also be used for molecular MR imaging. Zhang et al. reported the fabrication of RGD-conjugated APTMS-coated USPIO nanoparticles and their applications to specifically targeting $\alpha_{v} \beta_{3}$ integrins, an important receptor family for tumor angiogenesis, by a clinical 1.5 T magnetic resonance scanner [49]. Compared to plain USPIO control, RGD-USPIO particles had a higher cell uptake capability for both internalization through the cell membrane and accumulation within endosomes. When incubated with HUVECs in vitro in the phantom imaging experiments, RGD-coupled USPIO particles exhibited a strong $T_{2}^{*}$ contrast enhancement in gelatin gels, and the signal intensity (SI) for control USPIO and RGD-USPIO plus free RGD showed relatively lower darkness, which indicated that the RGD-USPIO particles could efficiently reduce the relaxivity, decrease the grey scale and therefore resulted in improved MR imaging contrast in vitro. In addition, these fabricated RGD-specific APTMS-coated USPIOs could be used to visualize $\alpha_{v} \beta_{3}$ integrin expression and distinguish tumors with different angiogenic profiles in nude mice in vivo MR imaging (Figure 6). These binding specificities and imaging differences between RGD-USPIO and plain USPIO particles facilitated high efficient image contrast and provided a useful tool for monitoring molecular profiles of tumor vessels in angiogenesis by MRI.
SPECT/PET imaging has a major disadvantage of poor spatial resolution. In comparison, MRI images display satisfactory and anatomical structures in soft tissues and bones. Complementary SPECT-MRI/PET-MRI fused imaging modalities could potentially afford sufficient resolutions and high sensitivity. Weissleder et al. recently have developed trimodal imaging probes for PET, MRI, and fluorescence microscopy modalities [56, 57]. Multiple functionalities, including ${ }^{18} \mathrm{~F}_{-} \mathrm{PEG}_{3}$ radiotracer motif as a $\mathrm{PET}$ reporter and near-infrared fluorochrome, and azide group for "click" chemistry as a convenient approach for further modifications, could be incorporated on the surface of aminated polysaccaride layered cross-linked iron oxide (CLIO) nanoparticles for multiple imaging detections. Fused PETCT dynamic images displayed a clearly resolved anatomical registration and radiotracer distribution information in BALB/C mice. This multifunctional nanoplatform could be applied to imaging of macrophages in inflammatory atherosclerosis after slight modifications of radionuclide chelators and coating materials.

5.2. Quantum Dots. Quantum dots (QDs) are a kind of versatile optical imaging agents that are readily stabilized with surface modifications, and conjugated with targeting ligands along with magnetic coatings serving as bimodal imaging probes for efficacious imaging of tumor angiogenesis. Mulder et al. showed the synthesis of PEGylated, cyclic RGD-functionalized QDs with a water-soluble and paramagnetic micellular coating as a molecular imaging probe for MRI and fluorescence microscopy [58]. The hydrophobic CdSe/ZnS core/shell QDs were PEGylated and then immobilized with $\mathrm{Gd}^{3+}$-ion phospholipid micelles to render them water-soluble, biocompatible and MR-detectable. Maleimide functionalization ensured the following cyclic RGD peptide conjugation on the QDs surface for specifically targeting $\alpha_{v} \beta_{3}$-integrins overexpressed on the angiogenic endothelial cells and tumors. Satisfactory fluorescent imaging capability and prominent $T_{1}$-weighted contrast enhancement were observed in in vitro test assessment for angiogenic human umbilical vein endothelial cells (HUVECs).

Apart from that, quantum dots can be serving as useful carriers for drug and gene delivery. This suggests a bilateral character for quantum dots to transport drugs and simultaneously be detected optically. Bagalkot reported quantum dot-aptamer-doxorubicin (QD-Apt-DOX) conjugates for synchronous FRET-mediated imaging, therapy and sensing of drug delivery process [59]. The CdSe-ZnS core-shell QDs as optical imaging agents are surface functionalized with A10 RNA aptamer for specifically targeting prostate specific membrane antigen (PSMA) cancer cells. The intercalation of DOX within the A10 DNA aptamer resulted in the formation of QD-Apt-DOX conjugates. Due to a fluorescence resonance energy transfer (FRET) mechanism, the QD-Apt-DOX conjugates turned to be on "OFF" state and no fluorescence was detected. When internalized into the cancer cells, DOX, a widely used anthracycline drug, was gradually released and therefore recovered fluorescence detection by optical techniques, as well as inducing the therapeutic effect in the 
target cancer cells. By using this smart conjugates, molecular imaging of DOX delivery, location and simultaneous cancer therapy could be achieved.

Additionally, as quantum dots may be photosensitized for production of radicals upon absorption of visible light, they can also be used to in photodynamic therapy (PDT) and radiation therapy against various cancers. Juzenas reviewed several fundamental concepts and recent developments in these fields [60].

5.3. Gold Nanoparticles. Gold nanoparticles [61, 62] are a subtype in the nanoparticle family and have been studied over years. A wide range of gold nanoparticles, including nanorods, nanoshells, nanocages, and surface-enhanced Raman scattering (SERS) nanoparticles, have been wellinvestigated and found broad applications in nanomedicine. In particular, gold nanoparticles can be used as photothermal therapeutic agents and trigger controlled release of chemical drugs. The Hyeon group proposed using magnetic gold nanoshells (Mag-GNS) as a platform for MRI imaging and photothermal therapy of breast cancers [63]. The starting silica sphere provided amino groups for conjugation to BMPA via direct nucleophilic substitution. Gold seed nanoparticles were attached to the residue amino groups on the silica sphere. After gold shell growth, magnetic gold shell nanoparticles were synthesized following the linkage of AntiHER2/neu on the surface of Mag-GNS for targeting cancer cells. The MR imaging could be achieved and selectively killing of breast cancer cells were accomplished by NIR radiation.

The Yoo group also developed a rhodamine-encapsulated PLGA-Au-Mn nanocomposite for photothermal therapy and $T_{2}$ MRI contrast imaging [64]. Gold and manganese shells enabled the photothermal property and MR contrast enhancement. And the burst release of rhodamine, a model drug, could be activated upon NIR radiation.

5.4. Nanotubes. Graphitic carbon nanotubes exhibit potential medical imaging capabilities and also integrated diagnostic/therapeutic efficacies. Dai and coworkers reported the fabrication of single wall carbon nanotubes (SWCNTs) as photothermal therapeutic (PTT) agents [65]. Selective cancer cell destruction and intrinsic NIR-triggered cell killing capacity could be realized without any harmful effects to normal cells. Thus, this class of nanomaterials can be applied to drug delivery and targeted therapy for various cancers. Recently, their group engineered a new type of FeCO/singlegraphitic-shell nanocrystals for both MRI-NIR imaging and therapy [66]. A scalable chemical vapour deposition method was utilized to synthesize the nanocrystals, and multiple functionalities of these coreshell materials were made for magnetism and near-infrared optical absorbance. The fabricated nanocrystals provided ultrahigh saturation magnetization and remarkable $r_{1}$ and $r_{2}$ relaxivities in both $T_{1}$-weighted (positive contrast) and $T_{2}$-weighted (negativecontrast) MR images, compared to commercial MRI contrast agents.
In in vivo animal imaging experiments, FeCO/singlegraphitic-shell nanocrystals were injected into a rabbit. Longer circulation and better positive contrast enhancement at lower dosages were obtained. The near-infrared optical properties of $\mathrm{FeCO} /$ single-graphitic-shell nanocrystals under $\lambda=808 \mathrm{~nm}$ near-infrared laser radiation demonstrated significant temperature increase over time, which implied good capability to convert NIR photon energy into thermal energy. These characteristic profiles afford FeCO nanocrystals potential applications for in vivo multimodal diagnostic imaging, controlled drug release and effective NIR-triggered tumor destruction.

5.5. Dendrimers. Dendrimer is one kind of advanced materials used as MRI imaging contrast agents [67]. Polyamidoamine (PAMAM) is one of most extensively studied and widely used commercial dendrimeric compounds. Relatively easy chemical synthesis of different sizes of dendrimers, termed "generations" will permit a tuneable molecular structure for adjustable MR imaging applications. Boswell et al. synthesized a G3 PAMAM-based multimodal dendrimeric imaging nanoplatform and made tentative biological investigations for fluorescence, MRI and SPECT molecular imaging in melanoma xenografted nude mice [68]. Fluorescent dye (Alexa Fluor 594) and MR imaging chelator (1B4M DTPA) were consecutively conjugated to the amino groups on the external surface of PAMAM dendrimers. Cyclic RGD peptides were then bonded to render the multicovalency binding effect for $\alpha_{v} \beta_{3}$-integrins. Different building blocks in the dendrimeric nanoparticles could be modified according to practical imaging requirements. In vitro studies revealed appreciable capability of this macromolecule agent in both MRI and optical imaging. However, in in vivo experiments, unsatisfactory tumor uptake implied poor extravasation capability of these particles into tumors. This requires further structural modifications to meet an improved binding affinity for the targeted tumor cells.

Enormous efforts on development of dendrimer-based nanoparticles have been also made by Kobayashi and his colleagues $[69,70]$. They fabricated a type of G6 PAMAMbased nanoprobes with multimodal and multicolor potentials. The PAMAM dendrimer was designed as a platform to be linked to both radionuclides and optical fluorophores, and therefore allowed for dual-modality scintigraphic and five-color near-infrared optical lymphatic imaging using a multiple-excitation spectrally resolved fluorescence imaging technique. The incorporation of ${ }^{111}$ In radionuclide made it possible to provide semiquantitative distribution information, while optical imaging could provide qualitative visualization with acceptable spatial resolution. Although each nanoprobe has a similar structure and an identical chemical characteristics, multimodal imaging and multicolour resolution could be simultaneously achieved in vivo after one single injection of these nanoprobes were administered in nude mice. This powerful imaging tool could be encouraging people to explore more advanced multifunctional imaging probes. 


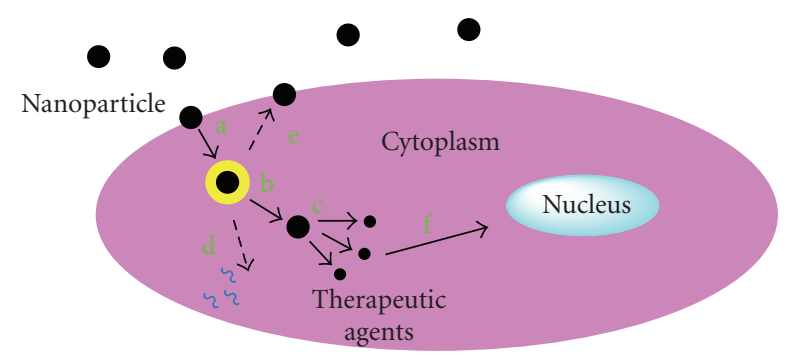

Figure 7: Cartoon for cytosolic delivery process of polymeric nanoparticles (NPs). (a) Cellular internalization of NPs; (b) Formation of lysosome-NPs by endocytosis; (c) Release of therapeutic agents in cytoplasm; (d) Degradation of agents; (e) Exocytosis of NPs; (f) Cytosolic transport of agents to targets.

5.6. Polymeric Micro-/Nanobubbles. Polymeric nanosized vectors are increasingly attractive for effective drug and gene delivery. Common small pharmaceutical compounds, therapeutic peptides and nucleic acids could be encapsulated as payloads into the polymeric nanocarriers. Compared to conventional viral vectors, polymeric nanoparticles might be biocompatible and biodegradable in vivo, and could avoid undesireable side effects, such as mutational virus insertion into host genome and development of replication competent viruses [71, 72]. However, as polymeric nanovectors may be cleared by the reticuloendothelial system (RES) due to the opsinization interactions in the blood stream, necessary surface modifications on the nanovectors will improve pharmacokinetics and lead to long circulating property. Figure 7 shows a series of representative intercellular delivery process of polymeric nanoparticles.

In ultrasonography, microbubbles can be used as imaging/diagnostic agents and make themselves as drug-loaded vehicles in the blood vessels for therapeutic purposes [7375]. In comparison to traditional soft shell microbubbles, hard shell polymeric microbubbles could provide higher stability to prevent gas diffusion and thus can be loaded with regular air instead of heavy gases. Palmowski et al. fabricated polymeric cyanoacrylate streptavidin-coated microbubbles, discussed the pharmacodynamics and found imaging and therapy applications in antiangiogenesis [76]. Following the polymerization of cyanoacrylate, streptavidin was coated on the surface to form polymer-stabilized microbubbles. Before administration, biotinylated antibodies (VEGFR2 and IgG) or peptides (RGD and RAD) were added to generate target-specific microbubbles as ultrasound contrast agents (Figure 8). Sensitive particle acoustic quantification (SPAQ)based quantitative analysis proved significant accumulation of RGD- and VEGFR2-conjugated microbubbles, compared with uncoated microbubbles and unspecific RAD- and IgG-controls. As for the imaging property, although the thicker and more robust polymer-stabilized shell would reduce the backscatter signal to a certain degree, this signal is strong enough to detect single microbubble in tissues and therefore enabled imaging with superb sensitivity.

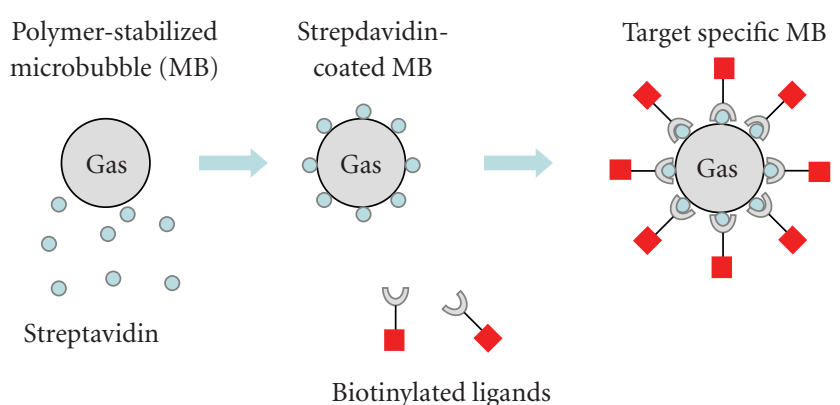

FIGURE 8: Schematic synthetic approach of target-specific microbubbles.

Afterwards two groups of animals were administered with these polymeric microbubbles to assess their antiangiogenic therapy effects. Before therapy started, no significant difference in the mean number of bound VEGFR2-specific and $\alpha_{v} \beta_{3}$ integrin-specific microbubbles was found between tumors of control and therapy group. Seven days after treatment, significantly increased binding of VEGFR2-specific microbubbles and $\alpha_{v} \beta_{3}$ integrin-specific microbubbles was observed in untreated tumors. In contrast, in treated tumors, accumulation of VEGFR2-specific microbubbles and $\alpha_{v} \beta_{3}$ integrin-specific microbubbles was reduced and significantly lower than that in control group. Thus these targeted microbubbles proved applicable to both effective molecular profiling of tumor angiogenesis and sensitive assessment of therapy in vivo.

Encouraged by these experimental findings, our group then made further explorations with these specific polymeric microbubble ultrasound contrast agents on imaging and therapy of early vascular response in prostate tumors irradiated with carbon ions (16 Gy) [77]. After injection of unspecific, RGD-coated and anti-ICAM-1-coated microbubbles, more significant accumulations were observed in tumor vessels bearing $\alpha_{v} \beta_{3}$ integrin and ICAM-1 receptors that for unspecific microbubbles. Retention of $\alpha_{v} \beta_{3}$ integrinand ICAM-1-specific microbubbles was evaluated by treating these microbubbles with the corresponding tumor cells after carbon ion irradiations. Significant increase of specific microbubbles within tumor vessels was found after 3-day carbon ion irradiation due to the induction of up-regulation of $\alpha_{v} \beta_{3}$ integrin and ICAM-1.

Microbubbles are regarded as the most popular contrast agents in ultrasound due to excellent acoustic backscattering properties of the gas core. Besides that, the encapsulation of paramagnetic MR imaging probes into the shell structure could facilitate a potential multimodal imaging capacity. Recently, Gu and his colleagues developed PLA-PVA doublelayered polymeric microbubbles with the encapsulation of superparamagnetic iron oxide $\left(\mathrm{Fe}_{3} \mathrm{O}_{4}, \mathrm{SPIO}\right)$ nanoparticles in the bubble shell $[78,79]$. The microbubble shell was $50-70 \mathrm{~nm}$ thickness and could afford the successful heterogeneous encapsulation of approximately $12 \mathrm{~nm}$ sized SPIO nanoparticles. The engineered double-layered 
SPIO-encapsulated microbubbles (EMBs) showed improved $r_{2}$ relaxivity and better contrast enhancement than SPIOfree microbubbles or SPIO-included microbubbles on the surface. The in vitro MRI experiments exhibited a gradient decrease of gray scale associated with a corresponding increase of the SPIO concentrations. And the transverse relaxation fitted well to a linear relationship with different SPIO-inclusion amounts in the microbubbles. Then in vitro ultrasound imaging was performed to observe a distinct "brightening" contrast enhancement in the region of interest (ROI) with a certain SPIO-EMBs concentration. After the injection of SPIO-EMBs into the liver of living rats, realtime MRI anatomical images demonstrated a clear negatively enhanced contrast subsequently over several time intervals. These exiting findings revealed a promising ultrasound-MRI dual modal imaging modality in medical applications.

To utilize microbubble-nanoparticle hybrid vehicles for drug release and therapy is another promising strategy for medical treatment applications [80]. Combination of microbubbles with nanoparticles into one single drug payload entity facilitates the possibility of effective drug transport from extracellular microenvironment to cell membrane, and controllable release at the diseased sites. A train of ultrasound pulses or radiation forces (RF) with certain pressure and frequency will lead to an enhanced permeability and retention effect (EPR) and significantly contribute to close proximity to vessel wall, internalization into the membrane, controllable burst of the microbubble shell, and targeted drug deposit site-specifically at the diseased regions. The Rapoport group described the applications of drugloaded nano/microbubbles for combined ultrasonography and targeted chemotherapy of breast cancer [81]. In this nonthermal therapeutic technique, perfluorocarbon nanodroplets with stabilization of block copolymers could be converted into nano/microbubbles upon heating. The phase state and size of bubbles could be controlled by different ratio of copolymer/gas core component. After the intravenous administration, strong and selective contrast was observed, and these bubbles could extravasate through leaky tumor vascular spaces. With oscillation and collapse of bubbles, encapsulated drugs could be controllably released, which consequently led to enhanced uptake by the targeted tumor cells.

5.7. Fullerene-Based Nanoparticles. Fullerene-based nanaoparticles are playing a more active role in modern medical imaging and therapeutic applications. For example, gadolinium-doped fullerenes and derivatives, such as $\mathrm{Gd@C} 82, \mathrm{Gd} @ \mathrm{C}_{82}(\mathrm{OH})_{22}, \mathrm{Gd} 3 \mathrm{~N} @ \mathrm{C}_{80}$, and $\mathrm{Gd} @ \mathrm{C}_{60}[\mathrm{C}(\mathrm{C}-$ $\left.\mathrm{OOH})_{2}\right]_{10}$ could be used as MR imaging contrast agents, and polonium-doped fullerenes act as candidate radiotracers in nuclear medicine $[82,83]$. On the other hand, after readily multifunctional modifications on the surface of fullerenes, they could be potential nanosized agents for medical gene therapies. Sitharaman and coworkers developed a new class of water-soluble $\mathrm{C}_{60}$ transfecting agents as gene-delivery vectors in vitro [84]. Three types of fullerenes with different chemical modifications via Hirsch-Bingel chemistry on the surface displayed positively, neutrally and negatively charged properties, respectively. Although all these $\mathrm{C}_{60}$ derivatives showed certain efficiency to transfect cells with DNA, only positively charged fullerenes exhibited efficient in vitro transfection. After reducing the aggregation and lowering the toxicity levels of these $\mathrm{C}_{60}$ fullerenes, it will offer great opportunity for them to serve as simultaneously diagnostic and therapeutic agents.

5.8. Rare-Earth Doped Nanoparticles. Recently, rare-earth doped nanoparticles have emerged as a fast-growing platform in cell trafficking and imaging due to low background noise for their near-infrared (NIR, $\lambda>760 \mathrm{~nm}$ ) emission. In particular, rare-earth oxide (REO) phosphor system has been widely studied so far. Meiser reported that $\mathrm{LaPO}_{4}$ nanoparticles were biofunctionalized via biotinavidin chemistry with good photostability and fluorescent properties [85]. Setua produced highly monodispersed $\mathrm{Eu}^{3+}$ and $\mathrm{Gd}^{3+}$ doped $\mathrm{Y}_{2} \mathrm{O}_{3}$ nanocrystals, and presented bi-modal imaging applications of both paramagnetism that enabled magnetic resonance imaging and bright red-fluorescence, aiding optical imaging of cancer cells, targeted specifically to their molecular receptors [86].

Rare-earth upconverting nanoparticles (UCNPs) have been developed as a new generation of luminescent labels due to their superb optical features, long lifetimes and excellent photostability [87]. Among various kinds of upconverting nanoparticles, $\mathrm{NaYF}_{4}$ is the most well-known system that has been employed in cellular and in vivo animal imaging [8890]. As this field is rapidly developing, we can expect that rare-earth doped nanoparticles will find their way into even more elaborate biotechnological applications in the coming future due to their relatively simple nanocomposition, deep penetration depth of NIR and other advantageous physical features. However, due to potentially high toxicity of lanthanides, more detailed investigations will be probably required to evaluate their biochemical and physiological behaviours before rare-earth doped nanoparticles are eventually translated for biomedical applications.

\section{Conclusion and Perspective}

Nanotechnology has been witnessing explosive growth, and the field of nanomedicine is undergoing revolutionary developments from traditional strategies to modern applications. However, several challenging issues still circumvent widespread biomedical uses of advanced nanotechnology. For example, novel multifunctional nanomaterials and improved treatment strategies are required to meet the needs of real-time, noninvasive imaging in living subjects or humans, and those of satisfactory drug delivery and therapy efficiency in vivo. Secondly, standardized nanoplatforms to be applied to diagnostic or therapeutic investigations of various diseases still have to be developed and formulated. More importantly, limited information has been obtained about the possible toxicity of nanoparticles and potential risks for the environment and human health up to date. It is quite urgent to evaluate the safety and the fate of nanomaterials in the body, so that rational and sufficient 
biological assessments could be concluded prior to ultimately translations into clinics. This will also be helpful for us to get a down-to-earth understanding and well-organized interpretation for biological and physiological processes. Considering the vast potential of nanoparticles in medicine, it is believed that nanomedicine will have a high impact on human life and contribute to the concept "small stuff makes big sense" in the coming future.

\section{Acknowledgment}

This work was financially supported by a grant of the BMBF (no. 0315481).

\section{References}

[1] G. Cao, Nanostructures \& Nanomaterials: Synthesis, Properties \& Applications, Imperial College Press, London, UK, 2004.

[2] M. Ferrari, "Cancer nanotechnology: opportunities and challenges," Nature Reviews Cancer, vol. 5, no. 3, pp. 161-171, 2005.

[3] National Nanotechnology Initiative, "What is nanotechnology?" http://www.nano.gov/html/facts/whatIsNano.html.

[4] D. Thassu, M. Deleers, and Y. Pathak, Nanoparticulate Drug Delivery Systems, Informa Healthcare, New York, NY, USA, 2007.

[5] V. E. Kagan, H. Bayir, and A. A. Shvedova, "Nanomedicine and nanotoxicology: two sides of the same coin," Nanomedicine: Nanotechnology, Biology, and Medicine, vol. 1, no. 4, pp. 313316, 2005.

[6] D. A. Mankoff, "A definition of molecular imaging," Journal of Nuclear Medicine, vol. 48, no. 6, pp. 18N-21N, 2007.

[7] R. P. Choudhary, V. Fuster, and Z. A. Fayad, "Molecular, cellular and functional imaging of atherothrombosis," Nature Reviews Drug Discovery, vol. 3, no. 11, pp. 913-925, 2004.

[8] F. A. Jaffer, P. Libby, and R. Weissleder, "Molecular and cellular imaging of atherosclerosis: emerging applications," Journal of the American College of Cardiology, vol. 47, no. 7, pp. 13281338, 2006.

[9] W. J. M. Mulder, D. P. Cormode, S. Hak, M. E. Lobatto, S. Silvera, and Z. A. Fayad, "Multimodality nanotracers for cardiovascular applications," Nature Clinical Practice Cardiovascular Medicine, vol. 5, no. 2, pp. S103-S111, 2008.

[10] V. P. Torchilin, "Multifunctional nanocarriers," Advanced Drug Delivery Reviews, vol. 58, no. 14, pp. 1532-1555, 2006.

[11] P. Alivisatos, "The use of nanocrystals in biological detection," Nature Biotechnology, vol. 22, no. 1, pp. 47-52, 2004.

[12] E. Yaghini, A. M. Seifalian, and A. J. MacRobert, "Quantum dots and their potential biomedical applications in photosensitization for photodynamic therapy," Nanomedicine, vol. 4, no. 3, pp. 353-363, 2009.

[13] I. J. Majoros, C. R. Williams, and J. R. Baker Jr., "Current dendrimer applications in cancer diagnosis and therapy," Current Topics in Medicinal Chemistry, vol. 8, no. 14, pp. 11651179, 2008.

[14] G. A. Koning and G. C. Krijger, "Targeted multifunctional lipid-based nanocarriers for image-guided drug delivery," Anti-Cancer Agents in Medicinal Chemistry, vol. 7, no. 4, pp. 425-440, 2007.
[15] X. Huang, P. K. Jain, I. H. El-Sayed, and M. A. El-Sayed, “Gold nanoparticles: Interesting optical properties and recent applications in cancer diagnostics and therapy," Nanomedicine, vol. 2, no. 5, pp. 681-693, 2007.

[16] A. A. Shvedova, E. R. Kisin, D. Porter, et al., "Mechanisms of pulmonary toxicity and medical applications of carbon nanotubes: two faces of Janus?" Pharmacology and Therapeutics, vol. 121, no. 2, pp. 192-204, 2009.

[17] S. Qin, C. F. Caskey, and K. W. Ferrara, "Ultrasound contrast microbubbles in imaging and therapy: physical principles and engineering," Physics in Medicine and Biology, vol. 54, no. 6, pp. R27-R57, 2009.

[18] M. Liong, J. Lu, M. Kovochich, et al., "Multifunctional inorganic nanoparticles for imaging, targeting, and drug delivery," ACS Nano, vol. 2, no. 5, pp. 889-896, 2008.

[19] E. Blanco, C. W. Kessinger, B. D. Sumer, and J. Gao, "Multifunctional micellar nanomedicine for cancer therapy," Experimental Biology and Medicine, vol. 234, no. 2, pp. 123131, 2009.

[20] R. Singh and K. Kostarelos, "Designer adenoviruses for nanomedicine and nanodiagnostics," Trends in Biotechnology, vol. 27, no. 4, pp. 220-229, 2009.

[21] I. I. Slowing, J. L. Vivero-Escoto, C.-W. Wu, and V. S.-Y. Lin, "Mesoporous silica nanoparticles as controlled release drug delivery and gene transfection carriers," Advanced Drug Delivery Reviews, vol. 60, no. 11, pp. 1278-1288, 2008.

[22] A. D. Durnev, "Toxicology of nanoparticles," Bulletin of Experimental Biology and Medicine, vol. 145, no. 1, pp. 72-74, 2008.

[23] R. Weissleder and U. Mahmood, "Molecular imaging," Radiology, vol. 219, no. 2, pp. 316-333, 2001.

[24] T. F. Massoud and S. S. Gambhir, "Molecular imaging in living subjects: seeing fundamental biological processes in a new light," Genes and Development, vol. 17, no. 5, pp. 545-580, 2003.

[25] X. Michalet, F. F. Pinaud, L. A. Bentolila, et al., "Quantum dots for live cells, in vivo imaging, and diagnostics," Science, vol. 307, no. 5709, pp. 538-544, 2005.

[26] J. W. M. Bulte and M. M. J. Modo, Nanoparticles in Biomedical Imaging: Emerging Technologies and Applications, Springer, New York, NY, USA, 2008.

[27] V. Ntziachristos, "Fluorescence molecular imaging," Annual Review of Biomedical Engineering, vol. 8, pp. 1-33, 2006.

[28] Z. Zhang, S. A. Nair, and T. J. McMurry, "Gadolinium meets medicinal chemistry: MRI contrast agent development," Current Medicinal Chemistry, vol. 12, no. 7, pp. 751-778, 2005.

[29] V. K. Varadan, L. Chen, and J. Xie, Nanomedicine: Design and Applications of Magnetic Nanomaterials, Nanosensors and Nanosystems, Wiley, London, UK, 2008.

[30] S. H. Bloch, P. A. Dayton, and K. W. Ferrara, "Targeted imaging using ultrasound contrast agents," IEEE Engineering in Medicine and Biology Magazine, vol. 23, no. 5, pp. 18-27, 2004.

[31] H. N. Wagner, Z. Szabo, and J. W. Buchanan, Principles of Nuclear Medicine, W. B. Saunders, Philadelphia, Pa, USA, 2nd edition, 1995.

[32] R. Essner, F. Daghighian, and A. E. Giuliano, "Advances in FDG PET probes in surgical oncology," Cancer Journal, vol. 8, no. 2, pp. 100-108, 2002.

[33] J. Cheon and J.-H. Lee, "Synergistically integrated nanoparticles as multimodal probes for nanobiotechnology," Accounts of Chemical Research, vol. 41, no. 12, pp. 1630-1640, 2008.

[34] G. T. Hermanson, Bioconjugate Techniques, Elsevier, New York, NY, USA, 2nd edition, 2008. 
[35] R. Sinha, G. J. Kim, S. Nie, and D. M. Shin, "Nanotechnology in cancer therapeutics: bioconjugated nanoparticles for drug delivery," Molecular Cancer Therapeutics, vol. 5, no. 8, pp. 1909-1917, 2006.

[36] Y. Liu, H. Miyoshi, and M. Nakamura, "Nanomedicine for drug delivery and imaging: a promising avenue for cancer therapy and diagnosis using targeted functional nanoparticles," International Journal of Cancer, vol. 120, no. 12, pp. 2527-2537, 2007.

[37] S. Laurent, D. Forge, M. Port, et al., "Magnetic iron oxide nanoparticles: synthesis, stabilization, vectorization, physicochemical characterizations and biological applications," Chemical Reviews, vol. 108, no. 6, pp. 2064-2110, 2008.

[38] L. Josephson, M. F. Kircher, U. Mahmood, Y. Tang, and R. Weissleder, "Near-infrared fluorescent nanoparticles as combined MR/optical imaging probes," Bioconjugate Chemistry, vol. 13, no. 3, pp. 554-560, 2002.

[39] A. Moore, Z. Medarova, A. Potthast, and G. Dai, "In vivo targeting of underglycosylated MUC-1 tumor antigen using a multimodal imaging probe," Cancer Research, vol. 64, no. 5, pp. 1821-1827, 2004.

[40] O. Veiseh, C. Sun, J. Gunn, et al., "Optical and MRI multifunctional nanoprobe for targeting gliomas," Nano Letters, vol. 5, no. 6, pp. 1003-1008, 2005.

[41] T.-J. Yoon, K. N. Yu, E. Kim, et al., "Specific targeting, cell sorting, and bioimaging with smart magnetic silica core-shell nanomaterials," Small, vol. 2, no. 2, pp. 209-215, 2006.

[42] J.-H. Lee, Y.-W. Jun, S.-I. Yeon, J.-S. Shin, and J. Cheon, "Dual-mode nanoparticle probes for high-performance magnetic resonance and fluorescence imaging of neuroblastoma," Angewandte Chemie - International Edition, vol. 45, no. 48, pp. 8160-8162, 2006.

[43] Y.-M. Huh, E.-S. Lee, J.-H. Lee, et al., "Hybrid nanoparticles for magnetic resonance imaging of target-specific viral gene delivery," Advanced Materials, vol. 19, no. 20, pp. 3109-3112, 2007.

[44] J.-S. Choi, Y.-W. Jun, S.-I. Yeon, H. C. Kim, J.-S. Shin, and J. Cheon, "Biocompatible heterostructured nanoparticles for multimodal biological detection," Journal of the American Chemical Society, vol. 128, no. 50, pp. 15982-15983, 2006.

[45] M. K. Yoo, I. Y. Kim, E. M. Kim, et al., "Superparamagnetic iron oxide nanoparticles coated with galactose-carrying polymer for hepatocyte targeting," Journal of Biomedicine and Biotechnology, vol. 2007, Article ID 94740, 9 pages, 2007.

[46] Y.-S. Lin, S.-H. Wu, Y. Hung, et al., "Multifunctional composite nanoparticles: magnetic, luminescent, and mesoporous," Chemistry of Materials, vol. 18, no. 22, pp. 5170-5172, 2006.

[47] C.-W. Lu, Y. Hung, J.-K. Hsiao, et al., "Bifunctional magnetic silica nanoparticles for highly efficient human stem cell labeling," Nano Letters, vol. 7, no. 1, pp. 149-154, 2007.

[48] C. Zhang, B. Wängler, B. Morgenstern, et al., "Silica- and alkoxysilane-coated ultrasmall superparamagnetic iron oxide particles: a promising tool to label cells for magnetic resonance imaging," Langmuir, vol. 23, no. 3, pp. 1427-1434, 2007.

[49] C. Zhang, M. Jugold, E. C. Woenne, et al., "Specific targeting of tumor angiogenesis by RGD-conjugated ultrasmall superparamagnetic iron oxide particles using a clinical 1.5-T magnetic resonance scanner," Cancer Research, vol. 67, no. 4, pp. 15551562, 2007.

[50] J. Xie, K. Chen, H.-Y. Lee, et al., "Ultrasmall c(RGDyK)-coated $\mathrm{Fe}_{3} \mathrm{O}_{4}$ nanoparticles and their specific targeting to integrin $\alpha_{\mathrm{v}} \beta_{3}$-rich tumor cells," Journal of the American Chemical Society, vol. 130, no. 24, pp. 7542-7543, 2008.
[51] G. Huang, C. Zhang, S. Li, et al., "A novel strategy for surface modification of superparamagnetic iron oxide nanoparticles for lung cancer imaging," Journal of Materials Chemistry, vol. 19, no. 35, pp. 6367-6372, 2009.

[52] J. S. Guthi, S.-G. Yang, G. Huang, et al., "MRI-visible micellar nanomedicine for targeted drug delivery to lung cancer cells," Molecular Pharmaceutics, vol. 7, no. 1, pp. 32-40, 2010.

[53] W. J. M. Mulder, A. W. Griffioen, G. J. Strijkers, D. P. Cormode, K. Nicolay, and Z. A. Fayad, "Magnetic and fluorescent nanoparticles for multimodality imaging," Nanomedicine, vol. 2, no. 3, pp. 307-324, 2007.

[54] M. Jugold, F. Kiessling, C. Zhang, B. Wangler, R. Pipkorn, and W. Semmler, "uPAR Selective Contrast Agent for Magnetic Resonance Imaging," European Patent no. EP1902734A1.

[55] J. Folkman, "Angiogenesis in cancer, vascular, rheumatoid and other disease," Nature Medicine, vol. 1, no. 1, pp. 27-31, 1995.

[56] M. Nahrendorf, H. Zhang, S. Hembrador, et al., "Nanoparticle PET-CT imaging of macrophages in inflammatory atherosclerosis," Circulation, vol. 117, no. 3, pp. 379-387, 2008.

[57] N. K. Devaraj, E. J. Keliher, G. M. Thurber, M. Nahrendorf, and R. Weissleder, " $18 \mathrm{~F}$ labeled nanoparticles for in vivo PETCT imaging," Bioconjugate Chemistry, vol. 20, no. 2, pp. 397401, 2009.

[58] W. J. M. Mulder, R. Koole, R. J. Brandwijk, et al., "Quantum dots with a paramagnetic coating as a bimodal molecular imaging probe," Nano Letters, vol. 6, no. 1, pp. 1-6, 2006.

[59] V. Bagalkot, L. Zhang, E. Levy-Nissenbaum, et al., "Quantum dot-aptamer conjugates for synchronous cancer imaging, therapy, and sensing of drug delivery based on Bi-fluorescence resonance energy transfer," Nano Letters, vol. 7, no. 10, pp. 3065-3070, 2007.

[60] P. Juzenas, W. Chen, Y.-P. Sun, et al., "Quantum dots and nanoparticles for photodynamic and radiation therapies of cancer," Advanced Drug Delivery Reviews, vol. 60, no. 15, pp. 1600-1614, 2008.

[61] M.-C. Daniel and D. Astruc, "Gold nanoparticles: assembly, supramolecular chemistry, quantum-size-related properties, and applications toward biology, catalysis, and nanotechnology," Chemical Reviews, vol. 104, no. 1, pp. 293-346, 2004.

[62] W. Cai, T. Gao, H. Hong, and J. Sun, "Applications of gold nanoparticles in cancer nanotechnology," Nanotechnology, Science and Applications, vol. 1, pp. 17-32, 2008.

[63] J. Kim, S. Park, J. E. Lee, et al., "Designed fabrication of multifunctional magnetic gold nanoshells and their application to magnetic resonance imaging and photothermal therapy," Angewandte Chemie - International Edition, vol. 45, no. 46, pp. 7754-7758, 2006.

[64] H. Park, J. Yang, S. Seo, et al., "Multifunctional nanoparticles for photothermally controlled drug delivery and magnetic resonance imaging enhancement," Small, vol. 4, no. 2, pp. 192196, 2008.

[65] W. S. Seo, J. H. Lee, X. Sun, et al., "FeCo/graphitic-shell nanocrystals as advanced magnetic-resonance-imaging and near-infrared agents," Nature Materials, vol. 5, no. 12, pp. 971976, 2006.

[66] J. H. Lee, S. P. Sherlock, M. Terashima, et al., "High-contrast in vivo visualization of microvessels using novel FeCo/GC magnetic nanocrystals," Magnetic Resonance in Medicine, vol. 62, no. 6, pp. 1497-1509, 2009.

[67] V. J. Venditto, C. A. S. Regino, and M. W. Brechbiel, "PAMAM dendrimer based macromolecules as improved contrast agents," Molecular Pharmaceutics, vol. 2, no. 4, pp. 302-311, 2005. 
[68] C. A. Boswell, P. K. Eck, C. A. S. Regino, et al., "Synthesis, characterization, and biological evaluation of integrin $\alpha_{v} \beta_{3}$ targeted PAMAM dendrimers," Molecular Pharmaceutics, vol. 5, no. 4, pp. 527-539, 2008.

[69] T. Barrett, G. Ravizzini, P. L. Choyke, and H. Kobayashi, "Dendrimers in medical nanotechnology," IEEE Engineering in Medicine and Biology Magazine, vol. 28, no. 1, pp. 12-22, 2009.

[70] H. Kobayashi, Y. Koyama, T. Barrett, et al., "Multimodal nanoprobes for radionuclide and five-color near-infrared optical lymphatic imaging," ACS nano, vol. 1, no. 4, pp. 258264, 2007.

[71] A. E. Nel, L. Mädler, D. Velegol, et al., "Understanding biophysicochemical interactions at the nano-bio interface," Nature Materials, vol. 8, no. 7, pp. 543-557, 2009.

[72] S. Kommareddy, S. B. Tiwari, and M. M. Amiji, "Longcirculating polymeric nanovectors for tumor-selective gene delivery," Technology in Cancer Research and Treatment, vol. 4, no. 6, pp. 615-625, 2005.

[73] J. R. Lindner, "Microbubbles in medical imaging: current applications and future directions," Nature Reviews Drug Discovery, vol. 3, no. 6, pp. 527-532, 2004.

[74] P. V. Kulkarni, C. A. Roney, P. P. Antich, F. J. Bonte, A. V. Raghu, and T. M. Aminabhavi, "Quinoline- $n-$ butylcyanoacrylate-based nanoparticles for brain targeting for the diagnosis of Alzheimer's disease," Wiley Interdisciplinary Reviews: Nanomedicine and Nanobiotechnology, vol. 2, no. 1, pp. 35-47, 2009.

[75] Q. Zhang, Z. Shen, and T. Nagai, "Prolonged hypoglycemic effect of insulin-loaded polybutylcyanoacrylate nanoparticles after pulmonary administration to normal rats," International Journal of Pharmaceutics, vol. 218, no. 1-2, pp. 75-80, 2001.

[76] M. Palmowski, J. Huppert, G. Ladewig, et al., "Molecular profiling of angiogenesis with targeted ultrasound imaging: early assessment of antiangiogenic therapy effects," Molecular Cancer Therapeutics, vol. 7, no. 1, pp. 101-109, 2008.

[77] M. Palmowski, P. Peschke, J. Huppert, et al., "Molecular ultrasound imaging of early vascular response in prostate tumors irradiated with carbon ions," Neoplasia, vol. 11, no. 9, pp. 856-863, 2009.

[78] F. Yang, L. Li, Y. Li, Z. Chen, J. Wu, and N. Gu, "Superparamagnetic nanoparticle-inclusion microbubbles for ultrasound contrast agents," Physics in Medicine and Biology, vol. 53, no. 21, pp. 6129-6141, 2008.

[79] F. Yang, Y. Li, Z. Chen, Y. Zhang, J. Wu, and N. Gu, "Superparamagnetic iron oxide nanoparticle-embedded encapsulated microbubbles as dual contrast agents of magnetic resonance and ultrasound imaging," Biomaterials, vol. 30, no. 23-24, pp. 3882-3890, 2009.

[80] S. Hernot and A. L. Klibanov, "Microbubbles in ultrasoundtriggered drug and gene delivery," Advanced Drug Delivery Reviews, vol. 60, no. 10, pp. 1153-1166, 2008.

[81] Z. Gao, A. M. Kennedy, D. A. Christensen, and N. Y. Rapoport, "Drug-loaded nano/microbubbles for combining ultrasonography and targeted chemotherapy," Ultrasonics, vol. 48, no. 4, pp. 260-270, 2008.

[82] R. D. Bolskar, "Gadofullerene MRI contrast agents," Nanomedicine, vol. 3, no. 2, pp. 201-213, 2008.

[83] J. Liu, S.-I. Ohta, A. Sonoda, et al., "Preparation of PEGconjugated fullerene containing $\mathrm{Gd}^{3+}$ ions for photodynamic therapy," Journal of Controlled Release, vol. 117, no. 1, pp. 104110, 2007.

[84] B. Sitharaman, T. Y. Zakharian, A. Saraf, et al., "Water-soluble fullerene (C60) derivatives as nonviral gene-delivery vectors," Molecular Pharmaceutics, vol. 5, no. 4, pp. 567-578, 2008.
[85] F. Meiser, C. Cortez, and F. Caruso, "Biofunctionalization of fluorescent rare-earth-doped lanthanum phosphate colloidal nanoparticles," Angewandte Chemie, vol. 116, no. 44, pp. 60806083, 2004.

[86] S. Setua, D. Menon, A. Asok, S. Nair, and M. Koyakutty, "Folate receptor targeted, rare-earth oxide nanocrystals for bi-modal fluorescence and magnetic imaging of cancer cells," Biomaterials, vol. 31, no. 4, pp. 714-729, 2010.

[87] F. Wang and X. Liu, "Recent advances in the chemistry of lanthanide-doped upconversion nanocrystals," Chemical Society Reviews, vol. 38, no. 4, pp. 976-989, 2009.

[88] Z. Li, Y. Zhang, and S. Jiang, "Multicolor core/shell-structured upconversion fluorescent nanoparticles," Advanced Materials, vol. 20, no. 24, pp. 4765-4769, 2008.

[89] Y. I. Park, J. H. Kim, K. T. Lee, et al., "Nonblinking and nonbleaching upconverting nanoparticles as an optical imaging nanoprobe and T1 magnetic resonance imaging contrast agent," Advanced Materials, vol. 21, no. 44, pp. 4467-4471, 2009.

[90] L.-Q. Xiong, Z.-G. Chen, M.-X. Yu, F.-Y. Li, C. Liu, and C.H. Huang, "Synthesis, characterization, and in vivo targeted imaging of amine-functionalized rare-earth up-converting nanophosphors," Biomaterials, vol. 30, no. 29, pp. 5592-5600, 2009. 

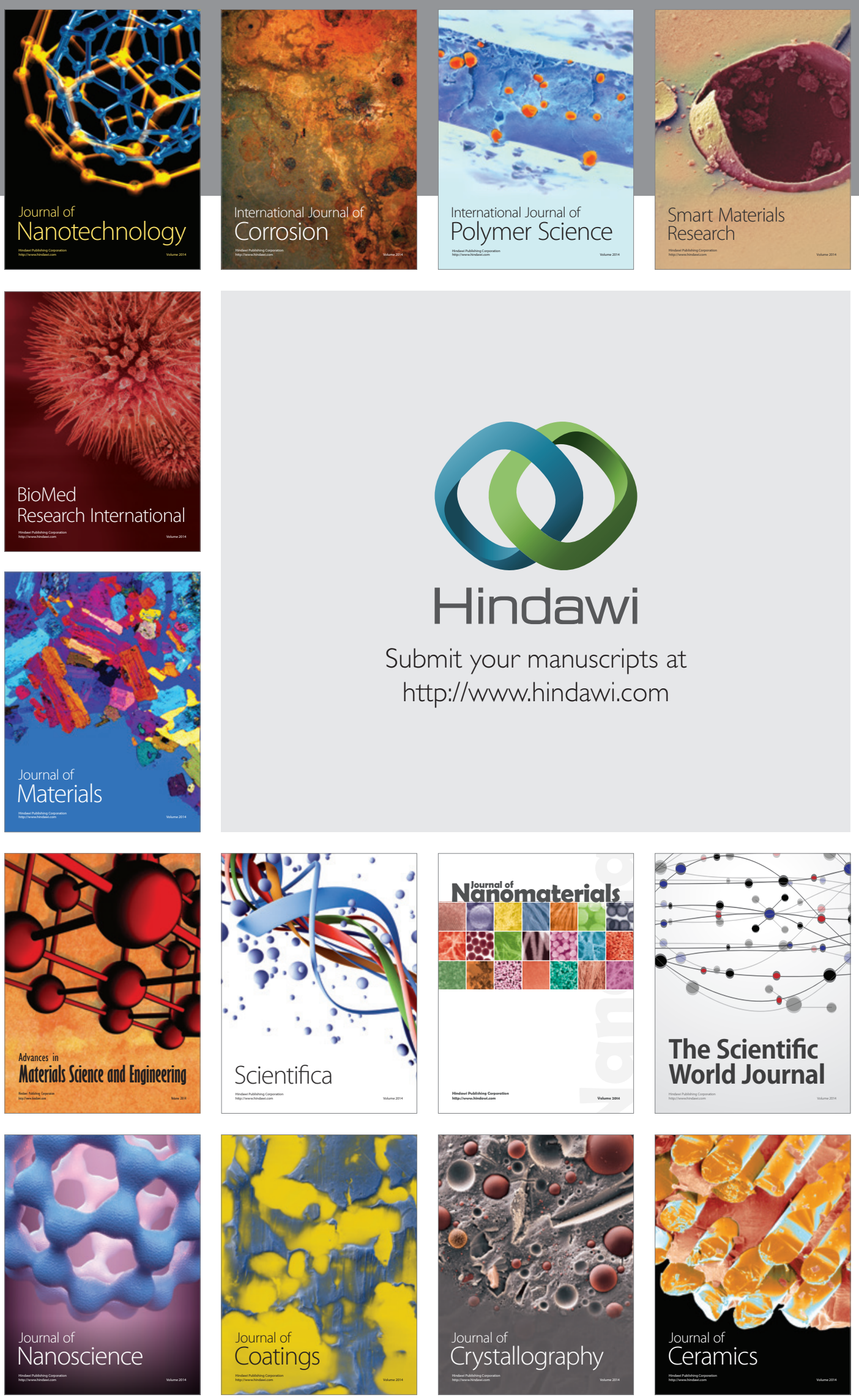

The Scientific World Journal

Submit your manuscripts at

http://www.hindawi.com

\section{World Journal}

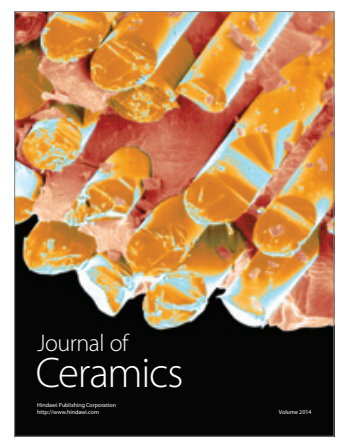

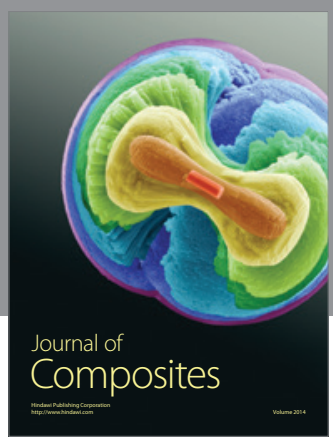
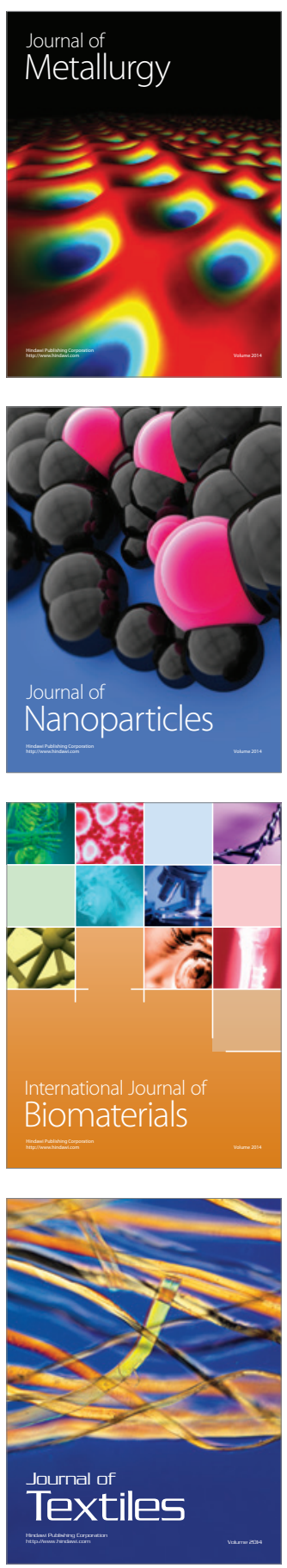